\title{
Clinical outcomes and temporal trends of immunological and non-immunological rare diseases in adult kidney transplant
}

\author{
Ester Gallo ${ }^{1}$, Silvia Mingozzi ${ }^{1}$, Alberto Mella ${ }^{1}$, Fabrizio Fop ${ }^{1}$, Roberto Presta ${ }^{1}$, Manuel Burdese ${ }^{1}$, Elena Boaglio ${ }^{1}$, \\ Maria Cristina Torazza', Roberta Giraudi', Gianluca Leonardi' , Antonio Lavacca' ', Paolo Gontero², \\ Omidreza Sedigh ${ }^{2}$, Andrea Bosio ${ }^{2}$, Aldo Verri $^{3}$, Caterina Dolla ${ }^{1}$ and Luigi Biancone ${ }^{1^{*}}$
}

\begin{abstract}
Background: Rare diseases (RDs) encompass many difficult-to-treat conditions with different characteristics often associated with end-stage renal disease (ESRD). However, data about transplant outcomes in adult patients are still lacking and limited to case reports/case series without differentiation between immunological/non-immunological RDs.

Methods: Retrospective analysis among all adult kidney transplanted patients (KTs) with RDs (RDsKT group) performed in our high-volume transplantation center between 2005 and 2016. RDs were classified according to the Orphanet code system differentiating between immunological and non-immunological diseases, also comparing clinical outcomes and temporal trends to a control population without RDs (nRDsKT).

Results: Among $1381 \mathrm{KTs}, 350$ patients (25.3\%) were affected by RDs (RDsKTs). During a f/up > 5 years [median 7.9years (4.8-11.1)], kidney function and graft/patient survival did not differ from nRDsKTs. Considering all posttransplant complications, RDsKTs (including, by definition, patients with primary glomerulopathy except on IgA nephropathy) have more recurrent and de-novo glomerulonephritis ( $14.6 \%$ vs. $9.6 \%$ in nRDskTs; $p=0.05$ ), similar rates of de-novo cancers, post-transplant diabetes, dysmetabolism, hematologic disorders, urologic/vascular problems, and lower infectious episodes than nRDsKTs (63.7\% vs $72.7 \% ; p=0.013)$. Additional stratification for immunological and non-immunological RDsKTs or transplantation periods (before/after 2010) showed no differences or temporal trends between groups.
\end{abstract}

Conclusions: Kidney transplant centers are deeply involved in RDs management. Despite their high-complex profile, both immunological and non-immunological RDsKTs experienced favorable patients' and graft survival.

Keywords: Rare diseases, Kidney transplantation, Genetic renal diseases, Survival, Primary glomerulonephritis

\footnotetext{
*Correspondence: luigi.biancone@unito.it

1 Renal Transplant Center "A. Vercellone," Nephrology, Dialysis, and Renal Transplant Division, "Città Della Salute e Della Scienza"Hospital, Department of Medical Sciences, University of Turin, Corso Bramante, 88-10126 Turin, Italy

Full list of author information is available at the end of the article
}

\begin{abstract}
Background
A medical condition in Europe is classified as a rare disease (RDs) if its prevalence is less than one case per 2000 $(0,05 \%)$ with an estimated incidence of two cases/100,000 inhabitants/year. According to this assumption, $\sim 5000$ 7000 RDs affect approximately 27 to 36 million people (6-8\%) of the European population [1]. Most of these conditions are genetically inherited and affect patients
\end{abstract}

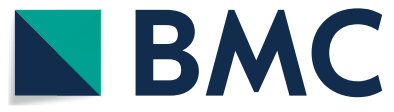

(c) The Author(s) 2021. Open Access This article is licensed under a Creative Commons Attribution 4.0 International License, which permits use, sharing, adaptation, distribution and reproduction in any medium or format, as long as you give appropriate credit to the original author(s) and the source, provide a link to the Creative Commons licence, and indicate if changes were made. The images or other third party material in this article are included in the article's Creative Commons licence, unless indicated otherwise in a credit line to the material. If material is not included in the article's Creative Commons licence and your intended use is not permitted by statutory regulation or exceeds the permitted use, you will need to obtain permission directly from the copyright holder. To view a copy of this licence, visit http://creativecommons.org/licenses/by/4.0/. The Creative Commons Public Domain Dedication waiver (http://creativeco mmons.org/publicdomain/zero/1.0/) applies to the data made available in this article, unless otherwise stated in a credit line to the data. 
for his/her entire lifetime [2, 3], posing both clinical and welfare issues (availability, affordability, and costs for diagnosis and treatment combined with adverse outcomes) $[1,4,5]$.

All these considerations pave the way for international initiatives to improve the healthcare needs of patients with RDs. In this context, the European Commission strongly suggests adopting the Orphanet classification system (ORPHA code) to classify RDs [6]. The Orpanet database encompasses more than 6700 RDs [7], including, beyond a classification system, much information about causative genes and possible therapeutic strategies (i.e., with orphan drugs).

In the nephrological setting, most glomerulonephritis could be classified as RDs; at the same time, many RDs could directly determine end-stage renal disease (ESRD) or be a crucial part of the clinical picture of ESRD patients. To date, the overall prevalence of renal replacement therapy (RRT) in Europe is estimated at 1000 per million population [8], but data about RDs in this population are scarce and outdated $[9,10]$. In the most recent paper by Wuhl et al. [3], derived from the ERA-EDTA Registry analysis, $12.4 \%$ of all RRT patients in the Euro area would be affected by RDs. Interestingly, although RDs have been frequently identified during the pediatric lifetime, only $5.8 \%$ of RRT patients were younger than 20 years [3].

Not surprisingly, epidemiological or survival analyses about kidney transplantation (KT) in RDs are still lacking; most of the available studies described case reports/ case series focusing on specific disease [11-14].

Our study aimed to (I) determine the prevalence of RDs in our population of adult KT recipients over time and (II) define whether and how the presence of RDs, also differentiating between immunological and nonimmunological conditions, influences the KT outcomes comparing this subgroup to the overall population.

\section{Methods}

\section{Study design and included population}

We conducted a retrospective analysis including all consecutive adult KTs performed at the Renal Transplant Center "A. Vercellone," AOU Città Della Salute e Della Scienza Hospital, Turin, in the period between 01/01/2005-31/12/2016. All pediatric KTs and patients without a determined cause of ESRD were excluded.

Based on the absence of a specific classification for RDs in RRT, we identified RDs in our population (RDsKT group) adopting the Orphanet database codification system (Table S1, Additional information). Therefore, all primary glomerulopathies were included except on IgA nephropathy (incidence rate 2.5/100000/year) [15]; patients without any histological assessment on native kidneys but with clinically documented hypertensive kidney disease and/or no features of immunological damage (i.e., no history of nephritic/nephrotic syndrome, hypocomplementemia, c- or p-ANCA, ANA, ENA, Ab anti-PLA ${ }_{2} \mathrm{R}$ or anti-GBM) were defined as "chronic glomerulopathy" and eventually included in the control group. CAKUT group merged patients with congenital renal dysplasia or hypoplasia with or without urinary tract malformation, chronic pyelonephritis due to congenital obstructive uropathy, or vesical-ureteric reflux without obstruction, and Prune-Belly syndrome. KTs with ESRD due to primary/secondary amyloidosis and the familial Mediterranean fever were all encompassed in the amyloidosis group.

To appropriately analyze this population's clinical characteristics and functional outcomes, we compared RDsKT to a control group of KTs without RDs (nRDsKT group) matched through a propensity score model (ratio 1:1; the decade of age at KT, number of living-donor, and previous kidney transplants as dependent variables). Figure 1a illustrates the selection process's flowchart.

We retrospectively analyzed the demographic and clinical characteristics of each group. All patient data were registered in our database and collected until 01/05/2019.

Evaluation of renal functional outcomes included serum creatinine $(\mathrm{sCr})$ and proteinuria $(\mathrm{uPt})$ at discharge and 1, 2, and 5 years after KT. Information about immunosuppressive therapy (also including induction protocol) was also collected.

Data about allograft biopsies, primarily performed for cause (i.e., significant or unexplained increase of $\mathrm{sCr}>25 \%$ from baseline, proteinuria, or both) were analyzed and reviewed according to the 2017 Banff classification [16]. Post-transplant glomerulonephritis cases were stratified as recurrent/de novo or undetermined cause based on available pre-transplant histological data.

For both groups, post-transplant complications (infectious episodes, de-novo cancers, post-transplant diabetes, dysmetabolism, hematologic disorders, urologic/ vascular problems), and patient/graft survival (including the cause of patients' death or allograft failure) were investigated.

The study was performed in adherence to the last version of the Helsinki Declaration and the Principles of the Declaration of Istanbul on Organ Trafficking and Transplant Tourism. All KT recipients signed informed consent, including their permission to have data from their medical records used in research. All the methods are approved by the institutional Ethical Committee (Comitato Etico Interaziendale A.O.U. Città Della Salute e Della Scienza di Torino - A.O. Ordine Mauriziano - A.S.L. Città di Torino) approval, resolution number 1449/2019 on 11/08/2019 ("TGT observational study"). 


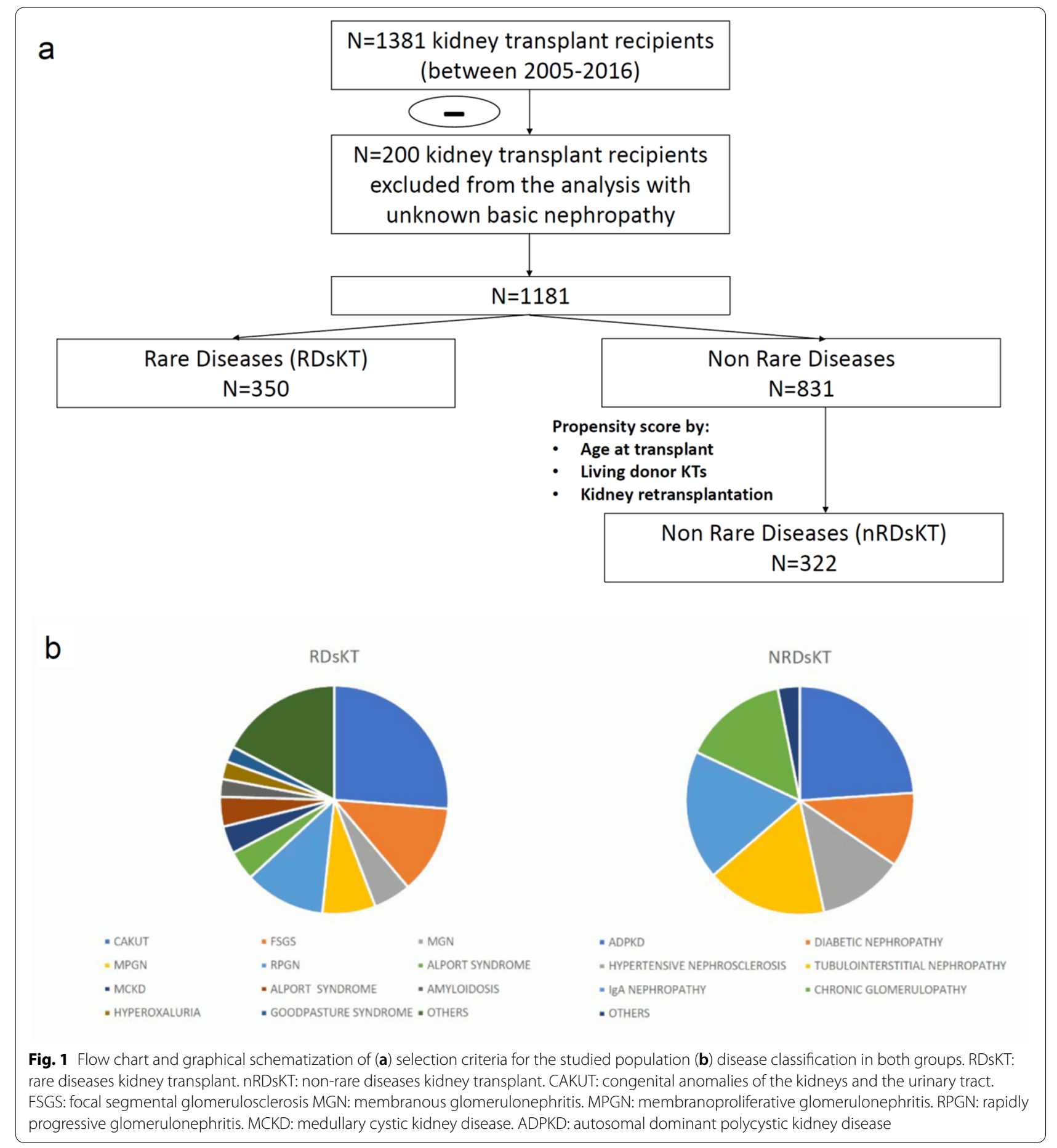

\section{Statistical analysis}

Statistical analysis was performed with SPSS (IBM SPSS Statistics, vers. 25.0.0). Continuous variables are presented, according to their distribution, as mean $\pm \mathrm{SD}$ or as median (min-max). Inter-group differences were analyzed with t-test or Mann-Whitney test, respectively.

We expressed categorical variables as fractions, and Pearson's $\chi^{2}$ or, for small samples, Fisher's exact test was 
Table 1 Demographic characteristics of the studied population at kidney transplant

\begin{tabular}{|c|c|c|c|}
\hline & $\begin{array}{l}\text { RDsKT } \\
n=350\end{array}$ & $\begin{array}{l}\text { nRDsKT } \\
n=322\end{array}$ & $p$ \\
\hline \multicolumn{4}{|l|}{ Recipient characteristics } \\
\hline Age at transplant (yrs), mean (SD) & $50.0(38.0-59.0)$ & $51.0(42.0-61.0)$ & 0.064 \\
\hline Gender male, N. (\%) & $208(59.4)$ & $202(62.7)$ & 0.380 \\
\hline Previous transplantation, N. (\%) & $68(19.4)$ & $54(16.8)$ & 0.106 \\
\hline Combined transplantation, N. (\%) & & & 0.005 \\
\hline+ heart & $1(0.3)$ & $0(0)$ & \\
\hline+ liver & $8(2.29)$ & $10(3.11)$ & \\
\hline+ pancreas & $0(0)$ & $13(4.04)$ & \\
\hline Time since dialysis (yrs), mean (SD) & $3.0(1.6-5.6)$ & $3.1(1.8-5.6)$ & 0.815 \\
\hline \multicolumn{4}{|l|}{ Donor characteristics } \\
\hline Age (yrs), mean (SD) & $55.0(45.0-65.0)$ & $57.0(48.0-67.0)$ & 0.052 \\
\hline Gender male, N. (\%) & $180(51.4)$ & $161(50)$ & 0.711 \\
\hline Deceased donor, N. (\%) & $318(90.9)$ & $300(93.2)$ & 0.271 \\
\hline Dual kidney transplantation, N. (\%) & $10(2.9)$ & $4(1.2)$ & 0.143 \\
\hline Delayed Graft Function ${ }^{a}$, N. (\%) & $76(22.6)$ & $73(23.2)$ & 0.866 \\
\hline \multicolumn{4}{|l|}{ Immunology at the time of transplantation } \\
\hline HLA mismatches, median (IQR) & $3(2-4)$ & $3(2-4)$ & 0.214 \\
\hline \multicolumn{4}{|l|}{ vPRA (\%), median (IQR) } \\
\hline Class I & $13.6(0.0-37.3)$ & $9.2(0.0-51.1)$ & 0.624 \\
\hline Class II & $1.88(0.0-46.1)$ & $0.5(0.0-51.6)$ & 0.851 \\
\hline Total & $27.1(4.8-72.4)$ & $35.7(4.8-72.4)$ & 0.716 \\
\hline $\begin{array}{l}\text { Time between the first evaluation at pre- } \\
\text { transplant unit and the active waiting-list } \\
\text { admittance (months) }{ }^{b} \text {, median (IQR) }\end{array}$ & 6.0 & $4.3(2.3-8.2)$ & 0.038 \\
\hline $\begin{array}{l}\text { Time on active waiting list (months), } \\
\text { median (IQR) }\end{array}$ & $9.5(3.0-26.1)$ & $8.6(3.1-28.0)$ & 0.886 \\
\hline Length of stay (days) ${ }^{\complement}$, median (IQR) & $17(13-26)$ & $18(14-26.75)$ & 0.720 \\
\hline Induction therapy & & & 0.440 \\
\hline No induction, N. (\%) & $2(0.6)$ & $1(0.3)$ & \\
\hline Anti-CD25 therapy, N. (\%) & $308(88.0)$ & $291(90.4)$ & \\
\hline Thymoglobuline, N. (\%) & $16(4.6)$ & $12(3.7)$ & \\
\hline $\begin{array}{l}\text { Anti-CD25 therapy+ Thymoglobuline, } \\
\text { N. (\%) }\end{array}$ & $16(4.6)$ & $8(2.5)$ & \\
\hline \multicolumn{4}{|l|}{ At discharge $^{d}$} \\
\hline Immunosuppressive therapy & & & 0.840 \\
\hline Tacrolimus, N. (\%) & $299(85.4)$ & $286(88.8)$ & \\
\hline $\begin{array}{l}\text { plus mycophenolate mofetil/azathio- } \\
\text { prine and steroids, N. (\%) }\end{array}$ & $242(72)$ & $225(71.2)$ & \\
\hline $\begin{array}{l}\text { plus mycophenolate mofetil/azathio- } \\
\text { prine or steroids, N. (\%) }\end{array}$ & $48(14.3)$ & $48(15.2)$ & \\
\hline Cyclosporine A, N. (\%) & $29(8.3)$ & $20(6.2)$ & \\
\hline $\begin{array}{l}\text { plus mycophenolate mofetil/azathio- } \\
\text { prine and steroids, N. (\%) }\end{array}$ & $19(5.7)$ & $14(4.4)$ & \\
\hline No Calcineurin inhibitor, N. (\%) & $8(2.3)$ & $10(3.1)$ & \\
\hline mTor inhibitor, N. (\%) & $6(1.7)$ & $28(8.7)$ & \\
\hline
\end{tabular}

VPRA Virtual panel reactive antibody, $\mathrm{s} C r$ Serum creatinine

${ }^{a}$ Intended as use of dialysis in the first week after kidney transplantation

${ }^{\mathrm{b}}$ Among 211 RDsKTs and 188 nRDsKTs transplanted from 2010 onwards, for whom data were available (109 and 82, respectively)

c Among 211 RDsKTs and 188 nRDsKTs transplanted from 2010 onwards, for whom data were available

${ }^{d}$ Among the 336 RDsKTs and 316 nRDsKTs with functioning kidney graft at discharge 
adopted to compare groups. The odds ratios (OR) with 95\% CI were used as a measure of relative risk.

Survival analysis was performed with the Kaplan-Meier method, comparing groups with the Log Rank test. The significance level $(\alpha)$ was set at $p<0.05$ for all tests.

\section{Results}

Prevalence of RDs and characteristics of the studied population

During the studied period, 350/1381 KTs (25.3\%) were performed in patients with RDs. The leading causes of ESRD in RDsKTs were CAKUT syndrome, focal segmental glomerulosclerosis, and rapidly progressive glomerulonephritis (Fig. 1b).

Table 1 shows baseline characteristics in RDsKTs and nRDsKTs, including the immunosuppressive regimen at transplantation (data stratified for RDs are available in Table S2, Additional information). No significant demographic difference was observed between groups, except for the higher number of combined KTs in the nRDsKT group, primarily determined by diabetic nephropathy and adult polycystic kidney disease (ADPKD) patients necessitating pancreas/kidney and liver/kidney transplant, respectively.

The mean recipient age and $\mathrm{M} / \mathrm{F}$ ratio were similar among groups $(48.8 \pm 13.4$ years in RDsKTs vs. $50.7 \pm 13.0$ in nRDsKTs, and $59.4 \%$ males vs. $62.7 \%$, respectively). Interestingly, RDsKTs experienced a long time between the first evaluation at our pre-transplant unit and the final admission on the active waiting list [6.0 months (3.5-10.1) vs. $4.3(2.3-8.2) ; p=0.038$ ].

Kidney function and immunosuppressive regimens at discharge and 1, 2, and 5 years post-KT are summarized in Table 2. Median $\mathrm{sCr}$ at discharge was slightly better in RDsKTs $(1.58 \mathrm{mg} / \mathrm{dL}$ vs. $1.72 \mathrm{mg} / \mathrm{dL}$ in RDsKT group; $p=0.026)$; during the $\mathrm{f} / \mathrm{up}$ time [7.9years $(4.8-11.1)$ in RDsKTs vs. 8.5 (5.3-11.5) in nRDsKTs] no significant differences in kidney function tests were observed at any time-point. No difference in maintenance immunosuppressive medications was even documented, also

Table 2 Kidney function and maintenance immunosuppressive therapy in studied population during the follow-up

\begin{tabular}{|c|c|c|c|}
\hline & RDsKT $(n=350)$ & $\operatorname{nRDsKT}(n=322)$ & $P$ \\
\hline \multicolumn{4}{|l|}{ At discharge } \\
\hline $\mathrm{sCr}(\mathrm{mg} / \mathrm{dL})$, median (IQR) & $1.58(1.27-2.00)$ & $1.72(1.30-2.10)$ & 0.026 \\
\hline Proteinuria (g/day), median (IQR) & $0.3(0.2-0.5)$ & $(0.2-0.5)$ & 0.581 \\
\hline \multicolumn{4}{|l|}{ At 1 year ${ }^{\mathrm{a}}$} \\
\hline $\mathrm{sCr}(\mathrm{mg} / \mathrm{dL})$, median (IQR) & $1.48(1.20-1.86)$ & $1.58(1.20-2.00)$ & 0.064 \\
\hline Proteinuria (g/day), median (IQR) & $0.19(0.12-0.30)$ & $0.19(0.12-0.33)$ & 0.587 \\
\hline \multicolumn{4}{|l|}{ At 2 years $^{b}$} \\
\hline $\mathrm{sCr}(\mathrm{mg} / \mathrm{dL})$, median (IQR) & $1.40(1.15-1.90)$ & $1.45(1.19-1.80)$ & 0.771 \\
\hline Proteinuria (g/day), median (IQR) & $0.18(0.12-0.33)$ & $0.20(0.12-0.34)$ & 0.891 \\
\hline \multicolumn{4}{|l|}{ At 5 years ${ }^{c}$} \\
\hline $\mathrm{sCr}(\mathrm{mg} / \mathrm{dL})$, median (IQR) & $1.40(1.15-1.90)$ & $1.44(1.15-1.90)$ & 0.826 \\
\hline Proteinuria (g/day), median (IQR) & $0.18(0.12-0.37)$ & $0.20(0.12-0.40)$ & 0.337 \\
\hline Immunosuppressive therapy & & & 0.209 \\
\hline Tacrolimus, N. (\%) & $174(82.9)$ & $178(82.4)$ & \\
\hline $\begin{array}{l}\text { plus mycophenolate mofetil/azathio- } \\
\text { prine and steroids, N. (\%) }\end{array}$ & $52[17]$ & $41(19.4)$ & \\
\hline $\begin{array}{l}\text { plus mycophenolate mofetil/azathio- } \\
\text { prine or steroids, N. (\%) }\end{array}$ & $76(36.5)$ & $77(36.5)$ & \\
\hline Cyclosporine A, N. (\%) & $17(8.1)$ & $18(8.3)$ & \\
\hline $\begin{array}{l}\text { plus mycophenolate mofetil/azathioprine } \\
\text { and steroids, N. (\%) }\end{array}$ & $5(2.4)$ & $5(2.4)$ & \\
\hline $\begin{array}{l}\text { plus mycophenolate mofetil/azathio- } \\
\text { prine or steroids, N. (\%) }\end{array}$ & $8(3.8)$ & $8(3.8)$ & \\
\hline No Calcineurin inhibitor, N. (\%) & $17(8.1)$ & $14(6.5)$ & \\
\hline mTor inhibitor, N. (\%) & $46(21.9)$ & $48(22.2)$ & \\
\hline
\end{tabular}

sCr Serum creatinine

a Among the 326 RDsKTs and 306 nRDsKTs with functioning kidney graft after one year from transplantation

${ }^{\mathrm{b}}$ Among the $315 \mathrm{RDsKTs}$ and $292 \mathrm{nRDsKTs}$ with functioning kidney graft after two years from transplantation

${ }^{\mathrm{C}}$ Among the 210 RDsKTs and $216 \mathrm{nRDsKTs}$ with functioning kidney graft after five years from transplantation 
Table 3 Post-transplant complications and kidney transplant outcomes in the studied population

\begin{tabular}{|c|c|c|c|}
\hline & $\begin{array}{l}\text { RDsKT } \\
n=350\end{array}$ & $\begin{array}{l}\text { nRDsKT } \\
n=322\end{array}$ & $P$ \\
\hline Glomerulonephritis, N. (\%) & $51(14.6)$ & $31(9.6)$ & 0.050 \\
\hline Recurrent, $\mathrm{N}$. & 30 & 14 & \\
\hline De novo, $\mathrm{N}$. & 11 & 10 & \\
\hline Undetermined, $\mathrm{N}$. & 10 & 7 & \\
\hline $\begin{array}{l}\text { Rejection (main histologic diagnosis) }{ }^{a}, \mathrm{~N} . \\
(\%)\end{array}$ & $66(18.9)$ & $62(19.3)$ & 0.900 \\
\hline AMR, N. & 47 & 39 & \\
\hline TCMR, N. & 19 & 23 & \\
\hline Infection ( $\geq 1$ episode), N. (\%) & $223(63.7)$ & $234(72.7)$ & 0.013 \\
\hline UTI, No. (\%) & $130(37.1)$ & $133(41.3)$ & 0.269 \\
\hline Recurrent UTI, N. (\%) & $47(13.4)$ & $39(12.1)$ & 0.610 \\
\hline Urosepsis, N. (\%) & $27(7.7)$ & $36(11.1)$ & 0.124 \\
\hline Viral infections, N. (\%) & $96(27.4)$ & $114(35.4)$ & 0.026 \\
\hline Tumors ( $\geq 1$ episode), N. (\%) & $52(14.9)$ & $58(18.0)$ & 0.270 \\
\hline Skin tumors, N. (\%) & $28(8.0)$ & $27(8.4)$ & 0.856 \\
\hline Solid tumors, N. (\%) & $24(6.8)$ & $31(9.6)$ & 0.191 \\
\hline Hematolymphoid tumors, N. (\%) & $1(0.3)$ & $4(1.2)$ & 0.149 \\
\hline Post-transplant diabetes, N. (\%) & $54(15.4)$ & $54(16.8)$ & 0.640 \\
\hline Post-transplant dysmetabolism, N. (\%) & $102(29.1)$ & $82(25.5)$ & 0.290 \\
\hline Hematologic complications, N. (\%) & 65 (18.6) & $60(18.6)$ & 0.980 \\
\hline Urologic complications, N. (\%) & $54(15.4)$ & $50(15.5)$ & 0.970 \\
\hline Vascular complications, N. (\%) & $30(8.6)$ & $40(12.4)$ & 0.100 \\
\hline Transplant failure, N. (\%) & $58(16.6)$ & $57(17.7)$ & 0.700 \\
\hline Chronic AMR, N. & 7 & 14 & \\
\hline Acute rejection, $\mathrm{N}$. & 5 & 6 & \\
\hline Glomerulonephritis (recurrent), $\mathrm{N}$. & 13 & 6 & \\
\hline Glomerulonephritis (de novo), N. & 2 & 1 & \\
\hline Interstitial fibrosis/tubular atrophy, N. & 4 & 9 & \\
\hline $\begin{array}{l}\text { Deceases with functioning kidney trans- } \\
\text { plant, N. (\%) }\end{array}$ & $23(6.6)$ & $28(8.7)$ & 0.300 \\
\hline Cardiovascular, $\mathrm{N}$. & 8 & 5 & \\
\hline Infection/sepsis, N. & 6 & 14 & \\
\hline Cancer, N. & 6 & 7 & \\
\hline Other, $\mathbf{N}$. & 3 & 2 & \\
\hline
\end{tabular}

AMR Antibody-mediated rejection, TCMR T-cell-mediated rejection, UTI Urinary Tract Infections

a Overall, rejection episodes observed in RDsKTs and nRDsKTs were 105 (76 [72.4\%] AMR and 25 [23.8\%] TCMR) and 90 (62 [68.9\%] AMR and 26 [28.9\%] TCMR), respectively

considering Mycophenolate Mofetil/Azathioprine and Steroids.

\section{Analysis of post-transplant complications and patient/ graft survival}

Clinical complications after KT are reported in Table 3. As expected, considering the adopted classification system, RDsKT group has a higher rate of recurrent and de-novo glomerulonephritis (14.6\% vs. 9.6\%; $p=0.05)$, mainly determined by patients with membranous nephropathy and focal-segmental glomerulosclerosis (57.9 and
$11.1 \%$ of recurrency, respectively) in RDs group and IgA nephropathy in nRDS group (71.4\%). Infectious episodes occurred more frequently in nRDsKTs $(p=0.013)$, mainly due to increased viral events in this group. Moreover, biopsy-proven rejection episodes (also stratifying for T-Cell/antibody-mediated subtypes), neoplasia (including skin, solid, and hematolymphoid tumors), post-transplant diabetes, and hematologic complications occurred without differences between RDsKTs and nRDsKTs.

Both patients and graft survival were strictly similar between groups (Fig. 2), also differentiating for RDs 


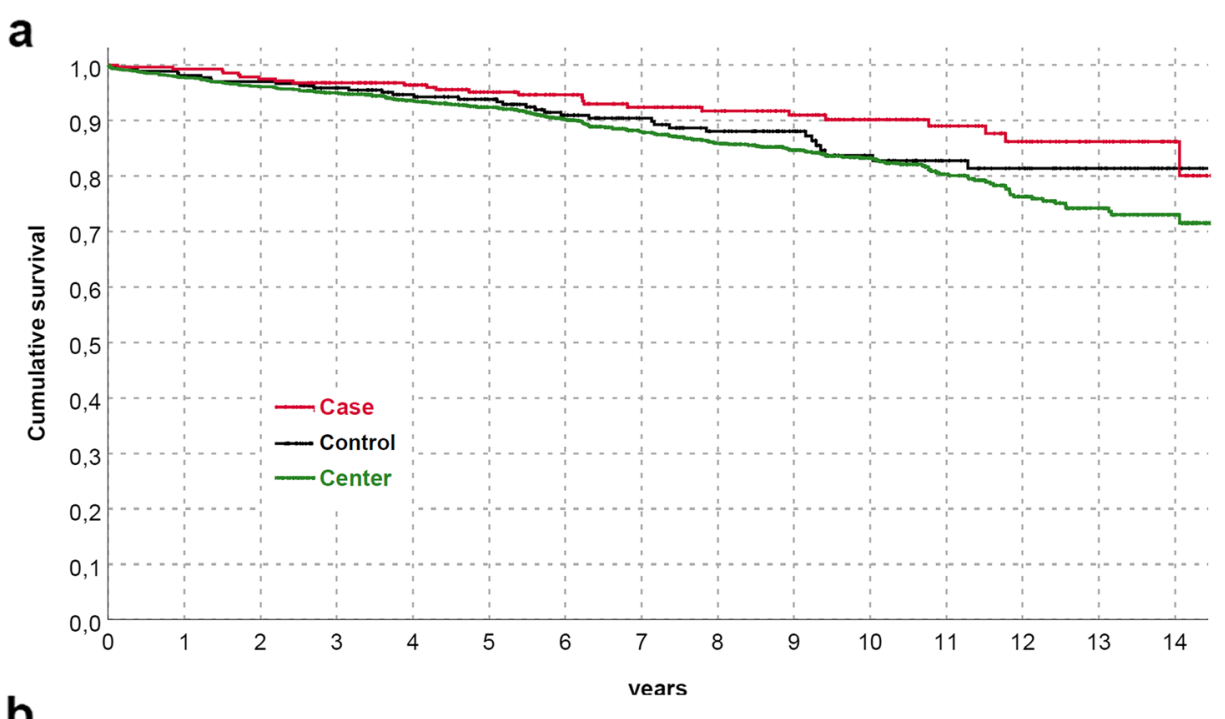

b

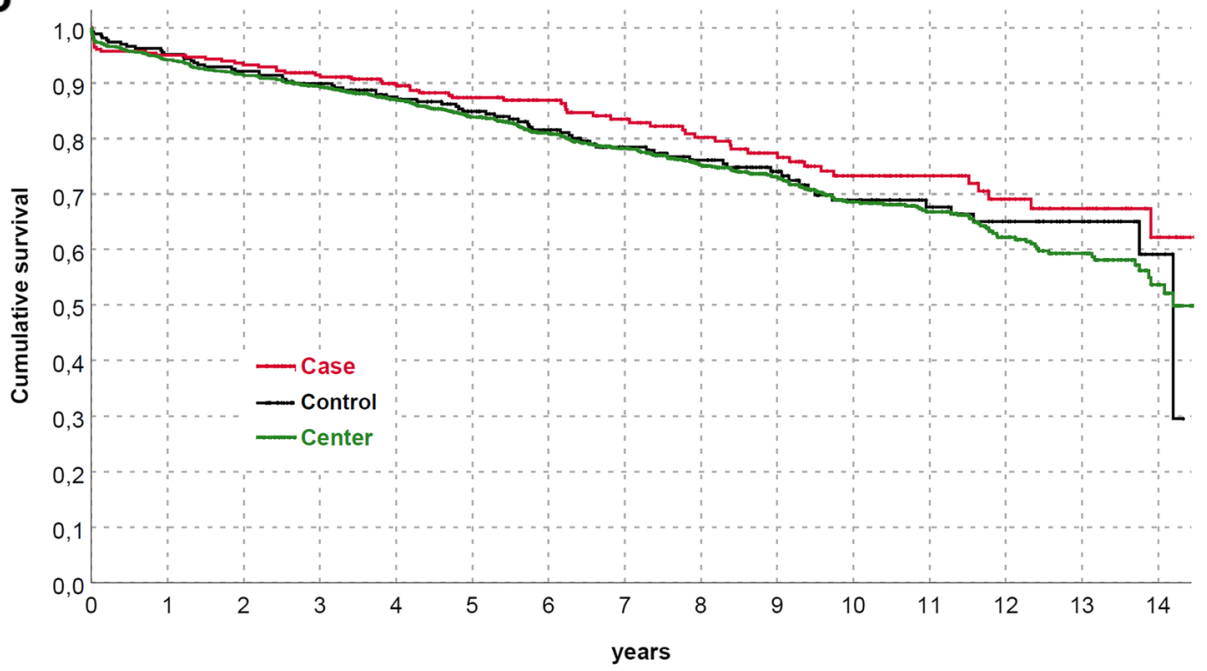

C

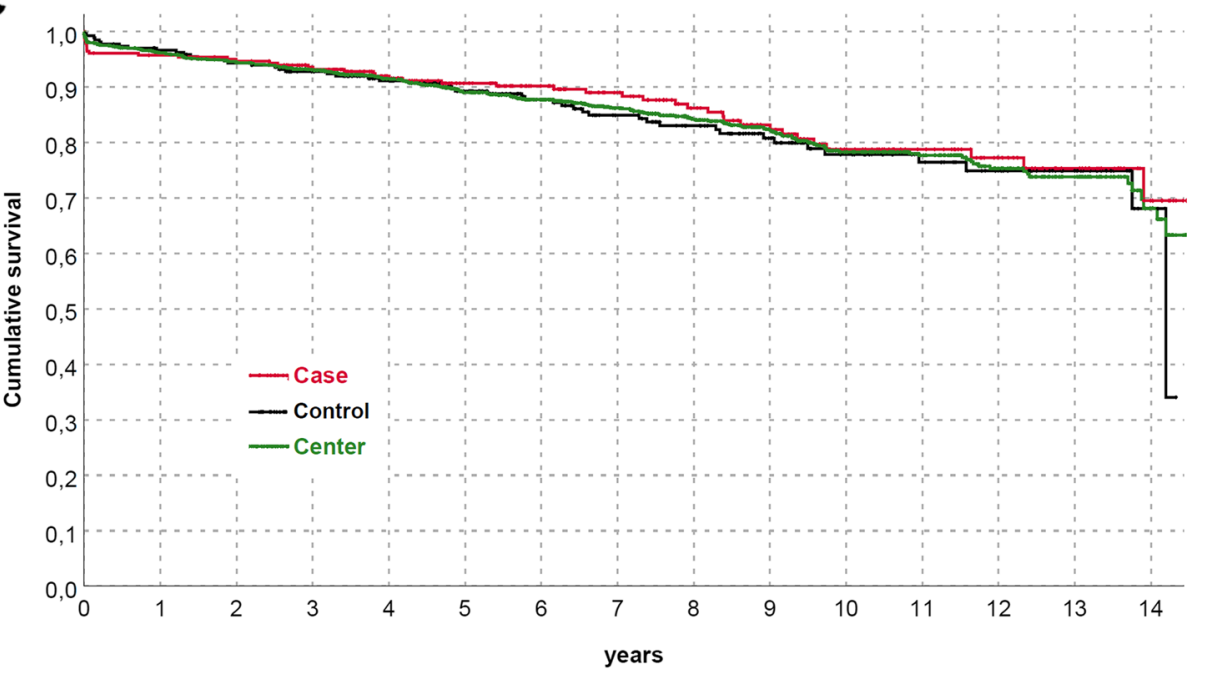

Fig. 2 Kaplan-Meier curves for (a) all studied population, (b) overall graft survival (c) death-censored graft survival. Patient and kidney survivals showed no differences between RDsKTs and nRDsKT $[p=0.156$ in (a); $p=0.245$ in (b); $p=0.488$ in (c) ] 


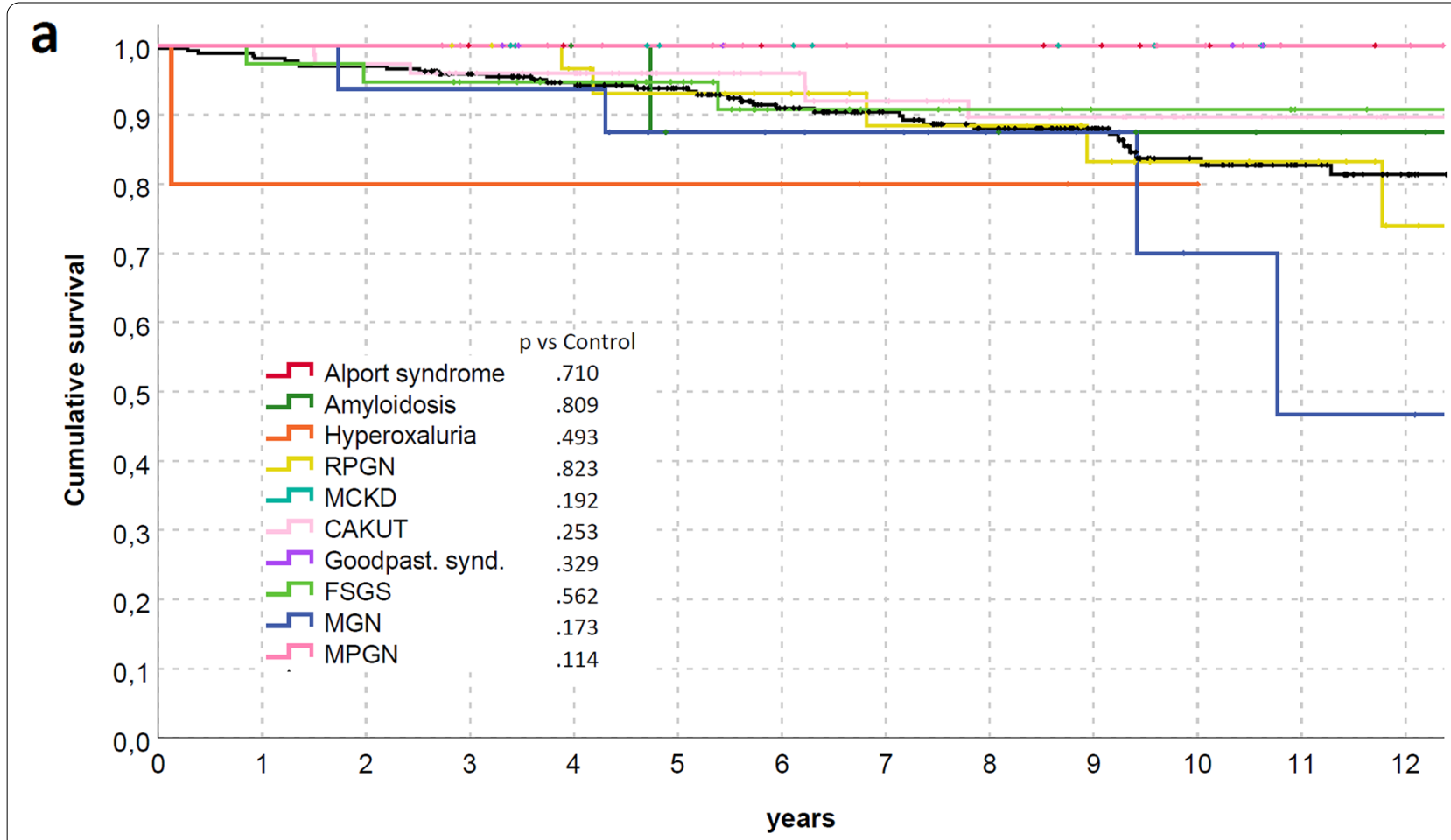

b

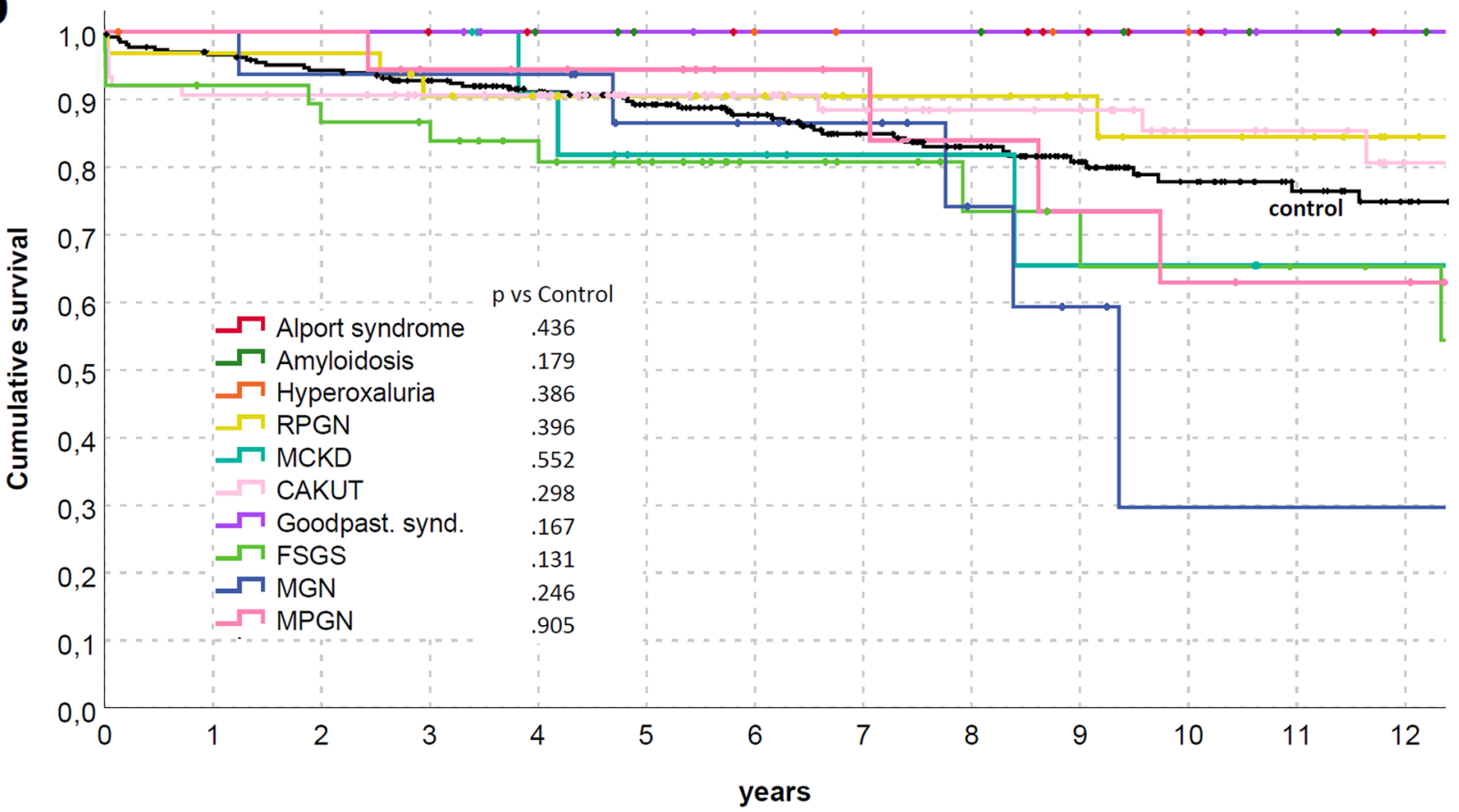

Fig. 3 Kaplan-Meier curves according to RDs for (a) patients (b) graft (death-censored). Patient and kidney survivals did not differ according to the type of rare disease and compared with the nRDsKT group

(Fig. 3) or between immunological and non-immunological conditions (Fig. 4). Similar trends were also observed comparing patients who received KTs before and after the median f/up time (Fig. 5). As expected, patients with recurrent/de-novo glomerulonephritis have a reduced graft survival, with a significant difference in RDs group (Fig. 6). No difference was already noted stratifying between recurrent and de novo conditions (Fig. 7). 


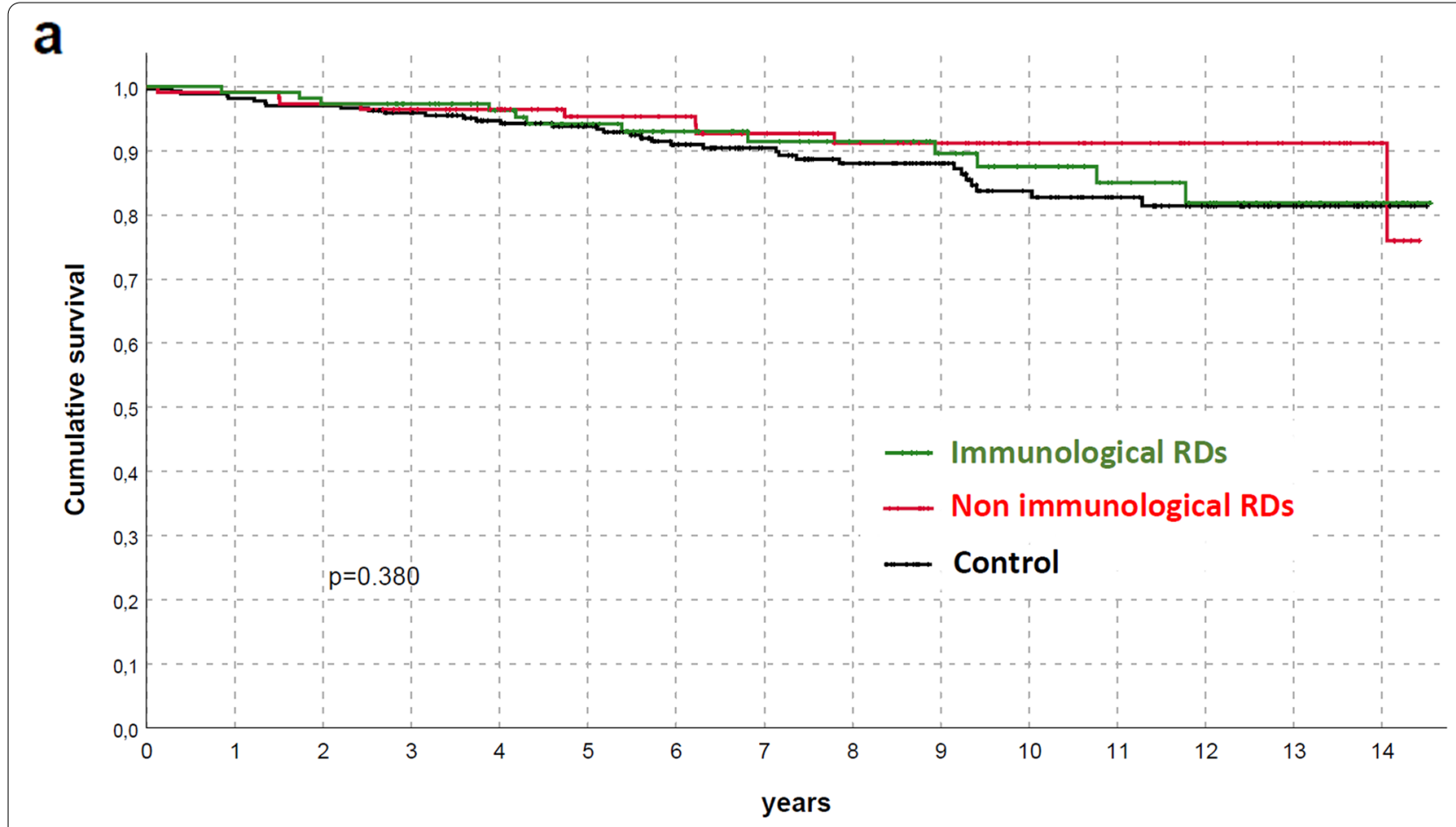

b

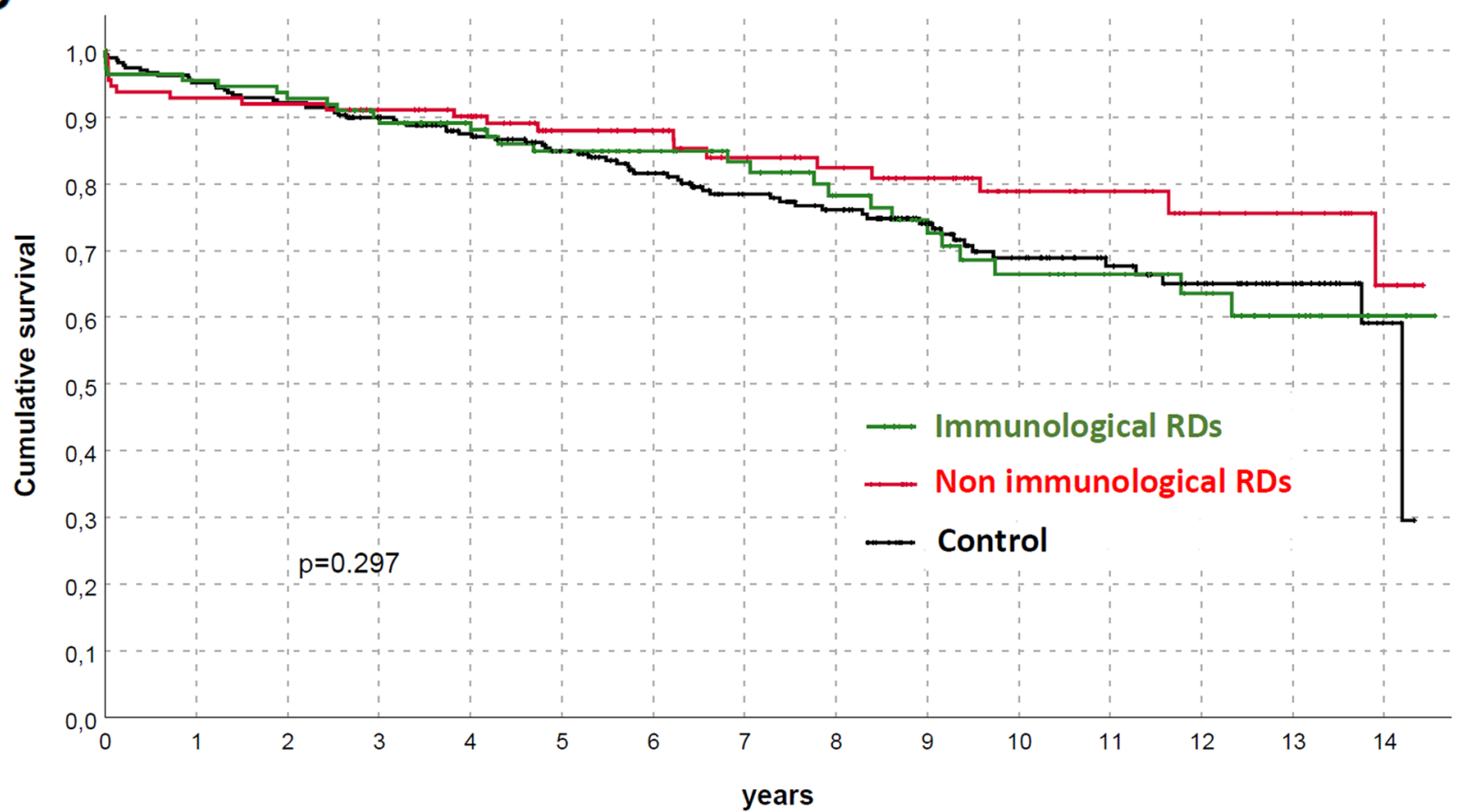

Fig. 4 Kaplan-Meier curves according to immunological and non-immunological RDs for (a) patients (b) graft (death-censored). Patient and kidney survivals did not differ between immunological and non-immunological RDs and compared with the nRDsKT group

At least 58 patients in the RDsKT group and 57 nRDsKTs experienced transplant failure; the leading causes were recurrent glomerulonephritis and chronic antibody-mediated rejection. Death with functioning graft occurred with similar percentages in both groups (6.6\% vs. $8.7 \% ; p=0.300)$. Deaths were mainly dependent 

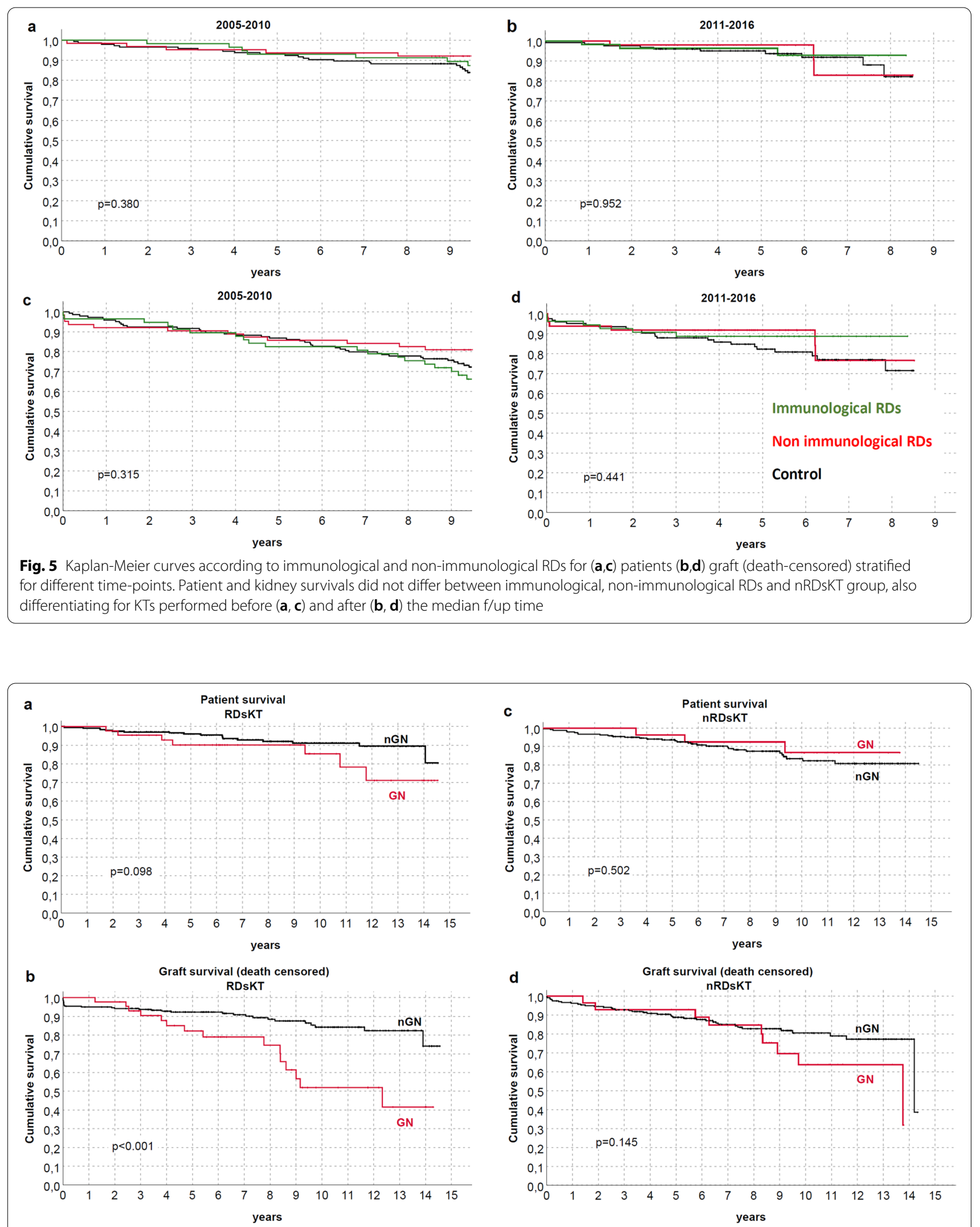

Fig. 6 Kaplan-Meier curves according to recurrent/de novo glomerulonephritis for $(\mathbf{a}, \mathbf{c})$ patients $(\mathbf{b}, \mathbf{d})$ graft (death-censored). Negative graft survival was observed in patients with recurrent/de novo glomerulonephritis (GN) vs. nGN among the RDsKT group $(p<0.001)$ 

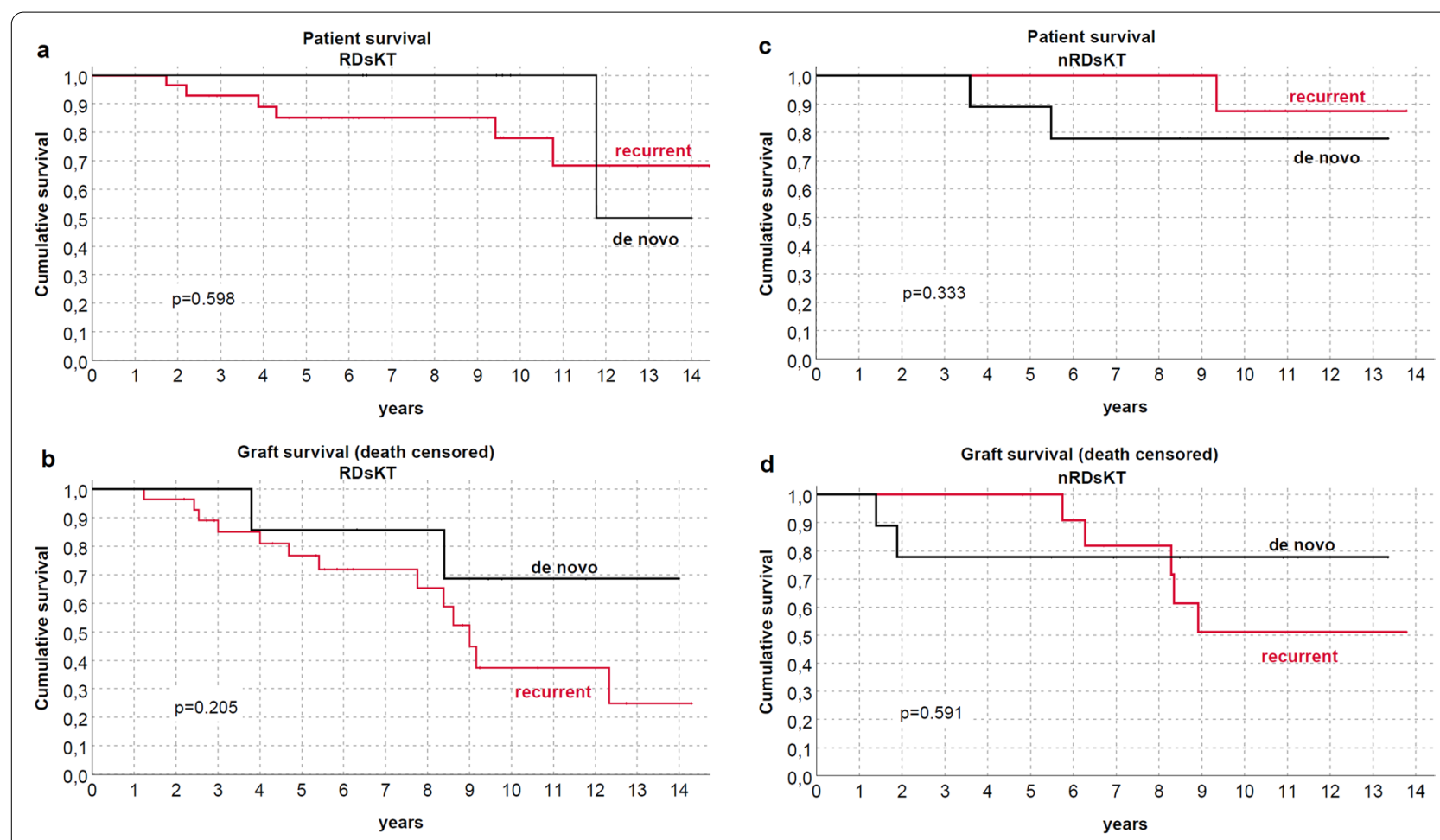

Fig. 7 Kaplan-Meier curves in recurrent and de novo glomerulonephritis for $(\mathbf{a}, \mathbf{c})$ patients $(\mathbf{b}, \mathbf{d})$ graft (death-censored). Patient and kidney survivals did not differ between recurrent and de novo glomerulonephritis in RDsKT and nRDsKT groups

Table 4 RDs prevalence in our kidney transplanted population compared to available data in the general population

\begin{tabular}{lll}
\hline Rare disease & $\begin{array}{l}\text { Kidney transplant }_{\text {recipients }^{\mathbf{a}}} \\
\text { (General } \\
\text { population [6, } \\
\mathbf{1 9}, \mathbf{2 0}\end{array}$ \\
\hline CAKUT & $6.8 \%$ & $0.1-0.3 \%$ \\
FSGS & $3.25 \%$ & Unknown \\
MGN & $1.37 \%$ & Unknown \\
MPGN & $1.95 \%$ & $0.01-0.05 \%$ \\
RPGN & $2.96 \%$ & Unknown \\
MCKD & $1.01 \%$ & $0.001-0.009 \%$ \\
ALPORT SYNDROME & $1.08 \%$ & Unknown \\
GOODPASTURE SYNDROME & $0.58 \%$ & $0.0001-0.0009 \%$ \\
HYPEROXALURIA & $0.65 \%$ & $0.0001-0.0009 \%$ \\
AMYLOIDOSIS & $0.65 \%$ & Unknown
\end{tabular}

CAKUT Congenital anomalies of the kidney and urinary tract, FSGS Focal segmental glomerulosclerosis, MGN Membranous glomerulonephritis, MPGN Membranoproliferative glomerulonephritis, RPGN Rapidly progressive glomerulonephritis, MCKD Medullar cystic kidney disease

a estimated on the studied population of consecutive adult KTs $(n=1381)$ performed at our center between January 2005 and December 2016 on septic events, cardiovascular or neoplastic complications without differences between RDsKTs and nRDsKTs.

\section{Discussion}

Identification, management, and treatment of RDs represent a challenging question for every health care system $[5,17,18]$. First of all, the heterogeneity of classification systems limited the generalizability of literature data. Furthermore, the difference in the availability of specific diagnostic testing (i.e., genetic analysis) reflects the high variability in RDs incidence, such as for Alport Syndrome [19].

All these considerations appear crucial in RRT patients considering that many ESRD causes could be categorizable as RDs. However, to the best of our knowledge, no study has to date specifically investigated the prevalence of RDs in adult KTs focusing on renal and patient outcomes and comparing them to the overall transplanted population.

Our analysis found that a significant number of KTs (25\% of all consecutive transplanted patients between January 2005 and December 2016) have a documented RDs (classified according to ORPHA code) as ESRD cause or significant medical condition. The prevalence of RDs, similar to Wuhl et al. [3], dramatically differs from those reported in the general population $[7,20,21]$ (Table 4). 
During the significant f/up time, RDsKTs experienced a favorable clinical course without differences in graft/ patient survival and kidney function tests compared to nRDsKTs, even stratifying for immunological and non-immunological conditions. Recurrent and de novo glomerulonephritis were effectively diagnosed in both groups, with a prevalent incidence of FSGS and MGN in RDs and IgA nephropathy in nRDs. All these conditions have a detrimental impact on graft survival $[22,23]$ which was more evident in RDs due to the higher occurrence and the more pronounced effect of some diseases (i.e., FGSG, MGN, and MPGN) on short-time graft outcomes [24-26].

Post-transplant complications apart from the expected higher rate of recurrent glomerulonephritis also occur similarly in both groups. We noted the absence of UTI increase in nRDs patients, which included subjects with CAKUT syndrome (normally exposed to increase UTI risk) [27]. Exploring this finding, we identified specific attention in this subgroup to antibiotic prophylaxis (which was generally prolonged to up to 1 week) and to a rapidly ureteral catheter/double J ureteral stent removal to prevent colonization.

However, although patients have similar rates of complications, the pre-transplant balance of RDs patients was longer, reflecting the need for a specific and time-consuming multidisciplinary approach (i.e., for correct pre-transplant diagnosis, analysis of all comorbid conditions, evaluation of possible recurrence rate on $\mathrm{KT}$, limitation in living donor transplantation for hereditary forms).

\section{Conclusions}

Transplant units are at the crossroads of not-so-rare RDs, resulting in significant involvement in their challenging management. However, RDs patients who received KTs have favorable outcomes with comparable complications and graft failure rates to those observed in nRDsKTs patients. Our data also strengthen the importance of an accurate monitorization to prevent/identify recurrent glomerulonephritis in those conditions at high risk (i.e., FSGS, MGN, MPGN) and rapidly diagnose de novo cases.

Further analyses (for example, introducing a tailored Transplant Registry for RDs within the Italian and international transplant community and implementing electronic health records [28]) are highly needed to expand and confirm our positive results.

\section{Abbreviations}

RDs: Rare diseases; ESRD: End-stage renal disease; KTs: Kidney transplanted patients; RDsKT: Kidney transplanted patients with rare diseases; nRDsKT: Kidney transplanted patients without rare diseases (control group); RRT
: Renal replacement therapy; ADPKD: Adult polycystic kidney disease (ADPKD).

\section{Supplementary Information}

The online version contains supplementary material available at https://doi. org/10.1186/s12882-021-02571-z.

Additional file 1: Table S1. Rare disease classification (according to Orpha-code) in the studied population. Table S2. Baseline characteristics and renal function tests among the most frequent RDs subgroups of the studied population.

\section{Acknowledgments}

Not applicable.

\section{Authors' contributions}

EG, SM, AM, RP, and LB contributed to the conception, design, analysis of the data and wrote the main manuscript text; FF performed the statistical analysis; $M B, E B, M C T, R G, G L, A L, P G, O S, A B, A V, C D$ revised the work critically for important intellectual content. All authors read and approved the final manuscript.

Funding

The authors declare that no funding was received for this study.

\section{Availability of data and materials}

The datasets used and/or analysed during the current study are available from the corresponding author on reasonable request.

\section{Declarations}

Ethics approval and consent to participate

The study was performed in adherence to the last version of the Helsinki Declaration and the Principles of the Declaration of Istanbul on Organ Trafficking and Transplant Tourism. All KT recipients signed informed consent, including their permission to have data from their medical records used in research. All the methods are approved by the institutional Ethical Committee (Comitato Etico Interaziendale A.O.U. Città Della Salute e Della Scienza di Torino - A.O. Ordine Mauriziano - A.S.L. Città di Torino) approval, resolution number 1449/2019 on 11/08/2019 ("TGT observational study").

Consent for publication

Not applicable.

\section{Competing interests}

The authors declare that they have no competing interests.

\section{Author details}

${ }^{1}$ Renal Transplant Center "A. Vercellone," Nephrology, Dialysis, and Renal Transplant Division, "Città Della Salute e Della Scienza" Hospital, Department of Medical Sciences, University of Turin, Corso Bramante, 88-10126 Turin, Italy. ${ }^{2}$ Division of Urology, Department of Surgical Sciences, Città Della Salute e Della Scienza Hospital and University of Turin, 10126 Turin, Italy. ${ }^{3}$ Division of Vascular Surgery, Department of Thoracic-Vascular Surgery, Città Della Salute e Della Scienza Hospital, 10126 Turin, Italy.

Received: 26 April 2021 Accepted: 19 October 2021

Published online: 17 November 2021

References

1. Commission of the European Community: COMMUNICATION FROMTHE COMMISSIONTOTHE EUROPEAN PARLIAMENT, THE COUNCIL, THE EUROPEAN ECONOMIC AND SOCIAL COMMITTEE ANDTHE COMMITTEE OF THE REGIONS on Rare Diseases: Europe's challenges. Available at: https:/ec.europa. eu/health/ph_threats/non_com/docs/rare_com_en.pdf, Aug 172020. 
2. Piano nazionale Malattie rare, Italian Health Department. Available at: http://www.salute.gov.it/portale/temi/p2_6.jsp?lingua=italiano\&id= 3296\&area=Malattie\%20rare\&menu=vuoto, Jul 082020.

3. Wühl E, Van Stralen KJ, Wanner C, Ariceta G, Heaf JG, Bjerre AK, et al. Renal replacement therapy for rare diseases affecting the kidney: An analysis of the ERA-EDTA Registry. Nephrol Dial Transplant. 2014;29:iv1-8.

4. Forman J, Taruscio D, Llera VA, Barrera LA, Coté TR, Edfäll C, et al. The need for worldwide policy and action plans for rare diseases. Acta Paediatr Int J Paediatr. 2012;101:805-7.

5. Aymé S, Bockenhauer D, Day S, Devuyst O, Guay-Woodford LM, Ingelfinger JR, et al. Common elements in rare kidney diseases: conclusions from a kidney disease: improving global outcomes (KDIGO) controversies conference. Kidney Int. 2017;92:796-808.

6. Rath A, Olry A, Dhombres F, Brandt MM, Urbero B, Ayme S. Representation of rare diseases in health information systems: the orphanet approach to serve a wide range of end users. Hum Mutat. 2012;33:803-8.

7. The portal for rare diseases and orphan drugs. Available at: www.orpha net, Aug 172020

8. Kramer A, Pippias M, Stel VS, Bonthuis M, Diez JMA, Afentakis N, et al. Renal replacement therapy in Europe: a summary of the 2013 ERA-EDTA registry annual report with a focus on diabetes mellitus. Clin Kidney J. 2016;9:457-69.

9. Nissenson AR, Port FK. Outcome of end-stage renal disease in patients with rare causes of renal failure. I inherited and metabolic disorders. Q J Med. 1989;74:1055-62.

10. Nissenson AR, Port FK. Outcome of end-stage renal disease in patients with rare causes of renal failure. III Systemic/vascular disorders. Q J Med. 1990;74:63-74.

11. Moray G, Tezcaner T, Özçay F, Baskın E, Akdur A, Kırnap M, et al. Liver and kidney transplant in primary hyperoxaluria: a single center experience. Exp Clin Transplant. 2015;13:145-7

12. Madiwale C, Murlidharan P, Hase N. Recurrence of primary hyperoxaluria: an avoidable catastrophe following kidney transplant. J Postgrad Med. 2008;54:206-8.

13. Dallos G, Chmel R, Alföldy F, Török S, Telkes G, Diczházi C, et al. Bourneville-Pringle disease for kidney transplantation: a single-center experience. Transplant Proc. 2006:38:2823-4.

14. Thibaud V, Rioux-Leclercq N, Vigneau C, Morice S. Recurrence of Goodpasture syndrome without circulating anti-glomerular basement membrane antibodies after kidney transplant, a case report 11 medical and health sciences 1103 clinical sciences. BMC Nephrol. 2019:20:4-8.

15. McGrogan A, Franssen CFM, De Vries CS. The incidence of primary glomerulonephritis worldwide: a systematic review of the literature. Nephrol Dial Transplant. 2011;26:414-30

16. Haas M, Loupy A, Lefaucheur C, Roufosse C, Glotz D, Seron D, et al. The Banff 2017 kidney meeting report: revised diagnostic criteria for chronic active $T$ cell-mediated rejection, antibody-mediated rejection, and prospects for integrative endpoints for next-generation clinical trials. Am J Transplant. 2018;18:293-307.

17. Taruscio D, Vittozzi L, Choquet R, Heimdal K, Iskrov G, Kodra Y, et al. National registries of rare diseases in europe: an overview of the current situation and experiences. Public Health Genomics. 2015;18:20-5.

18. Horgan D, Moss B, Boccia S, Genuardi M, Gajewski M, Capurso G, et al. Time for change? The why, what and how of promoting innovation to tackle rare diseases - is it time to update the EU's orphan regulation? And if so, what should be changed? Biomed Hub. 2020;5:1-11.

19. Rogowski WH, Grosse SD, Khoury MJ. Challenges of translating genetic tests into clinical and public health practice. Nat Rev Genet. 2009;10:48995. https://doi.org/10.1038/nrg2606.

20. Hogg R, Middleton J, Vehaskari VM. Focal segmental glomerulosclerosis - epidemiology aspects in children and adults. Pediatr Nephrol. 2007;22:183-6.

21. Nicolaou N, Renkema KY, Bongers EMHF, Giles RH, Knoers NVAM. Genetic, environmental, and epigenetic factors involved in CAKUT. Nat Rev Nephrol. 2015;11:720-31.

22. Infante B, Rossini M, Di Lorenzo A, Coviello N, Giuseppe C, Gesualdo L, et al. Recurrence of immunoglobulin a nephropathy after kidney transplantation: a narrative review of the incidence, risk factors, pathophysiology and management of immunosuppressive therapy. Clin Kidney J. 2020;13:758-67.

23. Lim WH, Shingde M, Wong G. Recurrent and de novo glomerulonephritis after kidney transplantation. Front Immunol. 2019;10:1-20.

24. De Souza L, Prunster J, Chan D, Chakera A, Lim WH. Recurrent glomerulonephritis after kidney transplantation. Curr Opin Organ Transplant. 2021; Publish Ahead of Print.

25. Uffing A, Pérez-Sáez MJ, Mazzali M, Manfro RC, Bauer AC. Drumond F de $S$, et al. recurrence of FSGS after kidney transplantation in adults. Clin J Am Soc Nephrol. 2020;15:247-56.

26. Wilson GJ, Cho Y, Teixiera-Pinto A, Isbel N, Campbell S, Hawley C, et al. Long-term outcomes of patients with end-stage kidney disease due to membranoproliferative glomerulonephritis: an ANZDATA registry study. BMC Nephrol. 2019;20:1-9.

27. Monteverde ML, Paz M, Ibáñez JP, Chaparro AB, Solernou V, Sager C, et al. Kidney transplantation in children with CAKUT and non-CAKUT causes of chronic kidney disease: do they have the same outcomes? Pediatr Transplant. 2020;24:1-12.

28. Garcelon N, Burgun A, Salomon R, Neuraz A. Electronic health records for the diagnosis of rare diseases. Kidney Int. 2020;97:676-86.

\section{Publisher's Note}

Springer Nature remains neutral with regard to jurisdictional claims in published maps and institutional affiliations.
Ready to submit your research? Choose BMC and benefit from:

- fast, convenient online submission

- thorough peer review by experienced researchers in your field

- rapid publication on acceptance

- support for research data, including large and complex data types

- gold Open Access which fosters wider collaboration and increased citations

- maximum visibility for your research: over 100M website views per year

At $B M C$, research is always in progress.

Learn more biomedcentral.com/submissions 